\title{
Measuring Central Venous Pressure Using the Proximal Lumen: An Audit
}

\author{
Piotr Orzylowski, Graeme Foggo, Peter O’Brien \\ Department of Anaesthetics \& Intensive Care, \\ University Hospital Crosshouse, Kilmarnock, Scotland
}

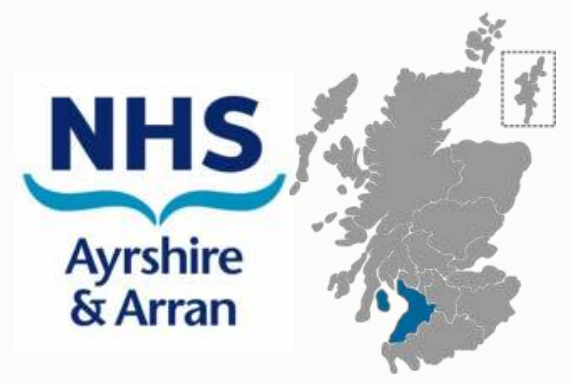

Background and Goal of Study:

The majority of Critical Care Units in the United Kingdom use the distal lumen for central venous pressure monitoring when using multi lumen central lines ${ }^{1}$. As previously discussed, this poses an increased risk in the event of central venous catheter (CVC) displacement or migration ${ }^{1}$. Although there may be differences in measurement, there is limited evidence to suggest any particular lumen is superior to others for CVP measurement ${ }^{2}$. Therefore, there has been a suggestion that the proximal lumen offers an added measure of safety and should be the lumen of choice for CVP measurement ${ }^{1,3}$. The aim of this audit was to measure compliance of CVP measurement using the proximal lumen in critical care units of NHS Ayrshire \& Arran.

Materials and Methods:

We prospectively performed daily checks on each CVC within the Intensive Care Unit (ICU) at University Hospital Crosshouse $(\mathrm{UHCH})$ and the ICU and High Dependency Unit at University Hospital Ayr (UHA), encompassing all critical care units of NHS Ayrshire \& Arran. The lumen being used for CVP measurement were documented. Data was collected between November 2016 and February 2017 at $\mathrm{UHCH}$, and between August 2017 and November 2017 at UHA

$\underline{\text { Results and Discussion: }}$

A total of 181 daily CVC checks were performed; 131 at $\mathrm{UHCH}$ and 50 at UHA. Proximal lumen were used only $60 \%$ of the time ( $66.4 \%$ at $\mathrm{UHCH}, 44 \%$ at UHA respectively). We identified this as a significant safety risk and changes are currently being implemented.

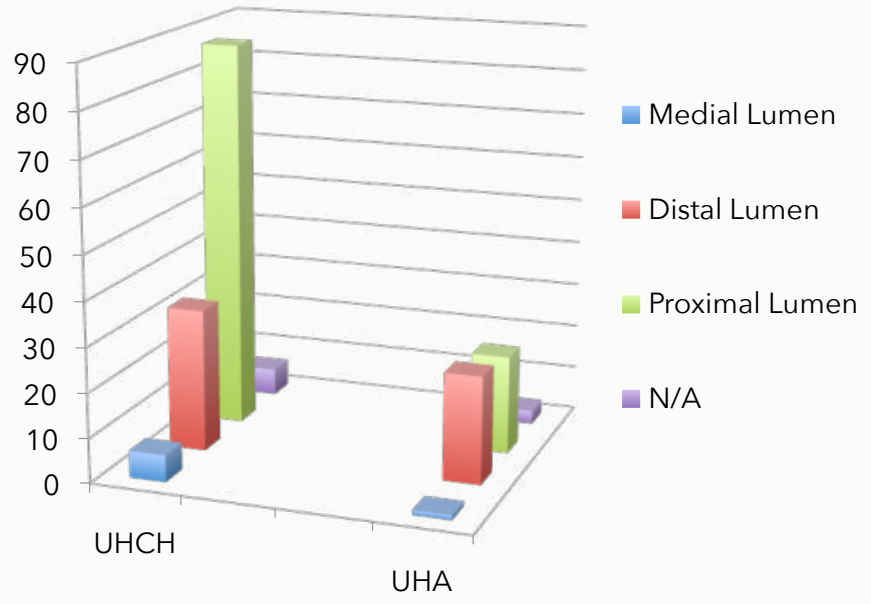

Chart 1: Lumen used for measuring CVP at $\mathrm{UHCH}$ \& UHA

Conclusion(s):

CVC displacement can lead to complications and death ${ }^{1}$. The use of proximal lumen for CVP measurement can reduce unnecessary risk to the patient by adding a mechanism for early warning in the event of migration or displacement. Despite this added measure of safety, many units throughout the United Kingdom, including our own, continue to use the distal or medial lumen for CVP measurement. We expect the implemented changes will lead to greater compliance with using the proximal lumen for CVP measurement, and translate to increased patient safety.

\section{$\underline{\text { References }}$}

1. K. Lake, C. Barker, P. Jefferson, DR Ball. Correspondence/ response to: Monitoring central venous pressure: proximal or distal lumen: a safety issue. Anaesthesia 2011; 66: $318-319$

2. Scott SS, Giuliano KK, Pysznik E, et al. Influence of port site on central venous pressure measurements from triple-lumen catheters in critically ill adults. Am J Crit Care. 1995;7:60-63

3. Alsafi A, Pahamin T, Selvarai I, Woollard C. Monitoring of central venous pressure via the proximal lumen: a safety issue. Anaesthesia 2010; 65:1241 